\title{
Severity of Parkinson's disease is a risk factor for peak-dose dyskinesia
}

\author{
M W I M Horstink, J C M Zijlmans, J W Pasman, H J C Berger, M A van't Hof
}

\begin{abstract}
Fifty four patients with idiopathic Parkinson's disease receiving levodopa therapy were studied. Thirty three of these patients displayed peak-dose dyskinesia. Neither the duration of Parkinson's disease nor the duration of levodopa therapy discriminated between patients with and patients without peakdose dyskinesia. Consequently, these criteria could not determine whether the first appearance of peak-dose dyskinesia depends on the duration of Parkinson's disease-a factor that is related to the severity of the disease- or on the duration of levodopa therapy.

A subgroup of nineteen patients with unilateral or unequivocally asymmetrical peak-dose dyskinesia was examined 12 hours after withdrawal of levodopa. A levodopa testdose provoked unilateral or unilateral preponderant peak-dose dyskinesia which always involved the most severely affected side and which also happened to be the side of onset of the disease. This demonstrates that the severity of Parkinson's disease is the main risk factor for peak-dose dyskinesia.
\end{abstract}

Peak-dose dyskinesia occurs in a substantial proportion of patients with Parkinson's disease on chronic levodopa treatment. During the early days of levodopa therapy patients were often treated with maximum tolerated doses, so peak-dose dyskinesia was usually a sign of acute overdose, which disappeared when the level of levodopa was reduced. Now, peak-dose dyskinesia usually becomes apparent at levodopa doses that did not initially provoke peak-dose dyskinesia, which suggests that other mechanisms than simple overdose must be involved. Peak-dose dyskinesia remains, however, dose related because it readily disappears when the levodopa dose is lowered. A form of pathological behavioural supersensitivity to levodopa seems to be involved: peak-dose dyskinesia is only seen in patients with PD or Parkinsonism. ${ }^{1-3}$ When levodopa is administered to patients without Parkinsonism or to normal controls, peak-dose dyskinesia does not occur. $^{4-8}$ This behavioural supersensitivity could be caused by nigrostriatal neuronal loss, which results in denervation supersensitivity and the failure of the degenerating presynaptic neurons to reuptake dopamine..$^{-11}$ However, most patients now being treated with levodopa have to be treated for years before peak-dose dyskinesia appears, which suggests that levodopa induced receptor supersensitivity could also be involved. Clinical evidence is available for both options, with the result that some authors conclude that the prevalence of peak-dose dyskinesia is related to the duration of levodopa therapy ${ }^{12-16}$ while others emphasise the natural progression of PD. ${ }^{17-21}$

In an attempt to answer the question of whether nigrostriatal neuronal loss, as reflected by the severity of PD, or the duration of levodopa therapy is the main risk factor for peak-dose dyskinesia, we evaluated both the duration of PD and the duration of levodopa therapy without peak-dose dyskinesia in patients with and without peak-dose dyskinesia. Furthermore, the severity of PD was separately assessed on the left and the right side in a subgroup of patients with unilateral or unequivocally asymmetrical peak-dose dyskinesia.

\section{Patients and methods}

Fifty four patients with idiopathic PD were studied. Each patient was regularly treated with levodopa plus decarboxylase inhibitor $\left(\right.$ Sinemet $^{R}$, Madopar $^{R}$ ) and each received $50 \mathrm{mg}$ orphenadrine- $\mathrm{HCl}$ three to five times daily. Patients with disabling end-of-dose akinesia took bromocriptine $5 \mathrm{mg}$ three to five times daily. In 19 patients with unilateral or unilaterally preponderant peak-dose dyskinesia, the severity of PD was assessed on both sides after discontinuation (with informed consent) of levodopa for twelve hours. On the evening before the assessment, the last normal daily therapy was administered at $6 \mathrm{pm}$, with the exception of levodopa. Madopar $125^{\mathrm{R}}$ or Sinemet $125^{\mathrm{R}}$ was administered at $10 \mathrm{pm}$ as many patients feared a disturbed night. At $7 \mathrm{am}$ on the morning of the assessment the patients received $50 \mathrm{mg}$ orphenadrine- $\mathrm{HCl}$. At $9.45 \mathrm{am}$ the severity of PD was assessed on both sides, at 10am Madopar 125 or Sinemet 125 was administered. From that time until $1.45 \mathrm{pm}$, the presence and location of peak-dose dyskinesia was studied. The severity of PD was assessed by five criteria: 1) the maximal tremor amplitude of each hand $(\mathrm{cm}) ; 2$ ) rigidity of each arm (absent, slight, moderate or severe); 3) tapping frequency for five seconds (leucocyte counter); 4) the number of seconds required to put eight pegs in a pegboard; 5) the number of pushes in five seconds on a push-button, made in turn by the palm and the back of the hand. To make the units of the five variables mutually 
Table 1 Characteristics of PD patients with and without peak-dose dyskinesia $(n=54)$

\begin{tabular}{llll}
\hline & $\begin{array}{l}\text { Without } \\
\text { dyskinesia }\end{array}$ & $\begin{array}{l}\text { With } \\
\text { dyskinesia }\end{array}$ & $\begin{array}{c}\text { p-value } \\
\text { (t test) }\end{array}$ \\
\cline { 2 - 4 } Number of patients & $\begin{array}{l}21 \\
\text { Mean }(S D)\end{array}$ & $\begin{array}{l}33 \\
\text { Mean }(S D)\end{array}$ \\
\hline Age at onset (yrs) & $56 \cdot 6(9 \cdot 8)$ & $51 \cdot 1(10 \cdot 1)$ & ns \\
Present age (yrs) & $62 \cdot 5(9 \cdot 7)$ & $61 \cdot 3(9 \cdot 1)$ & ns \\
Duration PD (yrs) & $5 \cdot 9(3 \cdot 9)$ & $10 \cdot 2(6 \cdot 6)$ & $<0 \cdot 01$ \\
Uncomplicated & $5 \cdot 9(3 \cdot 9)$ & $6 \cdot 4(3 \cdot 5)$ & ns \\
Duration L-Dopa (yrs) & $2 \cdot 8(1 \cdot 7)$ & $5 \cdot 8(5 \cdot 1)$ & $<0 \cdot 01$ \\
Uncomplicated & $2 \cdot 8(1 \cdot 7)$ & $2 \cdot 3(2 \cdot 2)$ & ns \\
\hline
\end{tabular}

Uncomplicated, years up to the outbreak of peak-dose dyskinesia or up to the date of examination in patients without peak-dose dyskinesia.

ns, not significant. table 2; eight patients had bilateral symmetrical peak-dose dyskinesia; nineteen patients had unilateral or unequivocally asymmetrical peakdose dyskinesia in which the upper extremity was involved. This asymmetry was confirmed during the observation period following administration of the levodopa dose. In these asymmetrical patients the severity of PD after discontinuation of levodopa appeared to be significantly worse on the dyskinetic or most dyskinetic side (table 3). This dyskinetic side was the side of onset of PD in all nineteen patients (table 2). In the bilaterally symmetrical dyskinetic patients, the hemiseverity of PD did not differ significantly between both sides [right side: $2 \cdot 1(0 \cdot 6)$; left side: $2 \cdot 1(0 \cdot 7)$; $p>0.05]$.

che group data of subscore into three categories of severity. The mean of all the categorised variables expressed the severity of PD in the individual patient. This severity grade (ranging from 1 to 3 ) is relative because only patients within the present sample were compared.

\section{Results}

Table 1 shows the characteristics of a group of 54 patients with idiopathic PD. Thirty three of these patients had a history of peak-dose dyskinesia. The total duration of PD and the total duration of levodopa therapy differed significantly between the groups. It was most striking that the duration of $\mathrm{PD}$ in patients without peak-dose dyskinesia and the duration of PD before the outbreak of peak-dose dyskinesia in dyskinetic patients did not differ significantly (table 1). Furthermore, the duration of levodopa therapy without peak-dose dyskinesia did not differ significantly between patients without peak-dose dyskinesia, 2.8 (1.7) years and patients with peak-dose dyskinesia, $2 \cdot 3(2 \cdot 2)$ years. Due to the marked correlation $(r=0.91)$ between the cumulative amount of levodopa prescribed and the duration of levodopa therapy, the total amount of levodopa was not included in this study.

Thirty three patients had peak-dose dyskinesia. Six patients had only cranial peak-dose dyskinesia, these patients are not included in

Table 2 The side of peak-dose hemidyskinesia and the side of onset of $P D(n=27)$

\begin{tabular}{lcl}
\hline \multirow{2}{*}{ Side of dyskinesia } & \multicolumn{2}{c}{ Side of onset of PD } \\
& Right & Left \\
\hline Right side & 14 & 0 \\
Left side & 0 & 5 \\
Bilateral & 3 & 5 \\
\hline Cross tabulation & Chi-square test: $\mathrm{p}<0.0001$.
\end{tabular}

Table 3 Hemiseverity mean ( $S D$ ) of $P D$ in patients with unilateral or unilateral preponderant peak-dose dyskinesia $(n=19)$

\begin{tabular}{|c|c|c|}
\hline & \multicolumn{2}{|l|}{ Side } \\
\hline & Dysk - & Dysk + \\
\hline Severity (1-3) & $1 \cdot 8(0 \cdot 7)$ & $2 \cdot 2(0 \cdot 7)^{\star}$ \\
\hline
\end{tabular}

\section{Discussion}

In the PD patients under study, peak-dose dyskinesia appeared after 6.4 (3.5) PD years (table 1). This period did not differ from the duration of PD in patients without peak-dose dyskinesia (table 1). Peak-dose dyskinesia became apparent after $2 \cdot 3(2 \cdot 2)$ years of levodopa treatment. The levodopa period without peak-dose dyskinesia did not differ from the duration of levodopa therapy in patients without peak-dose dyskinesia (table 1). Hence, our data concerning the delay to the onset of peak-dose dyskinesia in the total group of 54 patients indicates that it is either the duration of levodopa therapy that is important or the severity of PD, and the relevant importance of these two factors cannot be determined.

However, the investigation of patients with unilateral or asymmetrical peak-dose dyskinesia may answer the question. Since both duration and total amount of levodopa therapy are the same for both sides in the individual patients, levodopa therapy can be disregarded as the cause of the difference in the severity of peak-dose dyskinesia between the two sides. In this subgroup of 19 patients with unilateral or asymmetrical bilateral peak-dose dyskinesia it is clearly shown that the severity of PD is the dominant risk factor: in these patients the peakdose dyskinesia always appeared or predominated on the most severely affected side (table 3 ). Moreover, unilateral or unilateral preponderant peak-dose dyskinesia always appeared on the side of onset of PD (table 2). If the assumption can be made that the side of onset of PD is the most severely affected one, this observation confirms that severity of PD is the main risk factor for the development of peakdose dyskinesia.

1 Lang HE, Meadows JC, Parkes JD, Marsden CD Early onset of the "on-off" phenomenon in children with symptomatic parkinsonism. J Neurol Neurosurg with symptomatic parkin

2 Sacks O. Awakenings. London: Picador, Pan Books: 1982. dose-related fluctuations in presumed Olivopontodose-related fluctuations in presumed Olivop
cerebellar Atrophy. Movement Dis 1986;1:93-102.

4 Mena I, Court J, Fuenzalida S, Papavasiliou PS, Cotzias GC. Modification of chronic manganese poisoning treatment with L-dopa or 5-OH tryptophane. $N$ Engl Med J 1970;282:5-9. 
5 Klawans HL, Paulson GW, Ringel SP, Barbeau A. Use of levodopa in detection of presymptomatic Huntington's chorea. N Engl J Med 1972;286:1332-4.

6 Quaade F, Pakkenberg H, Juhl E. Levodopa as a treatment of obesity. Acta Med Scand 1974;195:129-30.

7 Chase TN, Holden EM, Brody JA. Levodopa-induced dyskinesias. Comparison in parkinsonism-dementia and amyotrophic lateral sclerosis. Arch Neurol 1973;29: 328-30

8 Markham CA. The choreoathetoid movement disorder induced by levodopa. Clin Pharmacol Ther 1971;12: 340-3.

9 Shaw KM, Lees AJ, Stern GM. The impact of treatment with levodopa in Parkinson's disease. $Q J$ Med 1980; 195:283-93.

10 Hornykiewics $O$. Compensatory biochemical changes at the striatal dopamine synapse in Parkinson's disease. Limitations of L-Dopa therapy, In: Poirier LJ, Sourkes TL, Bédard PJ, eds. The Extrapyramidal System and its Disorders. Adv in Neurol, vol 24. New York: Raven Press, 1979:275-81.

11 Mouradian MM, Chase TN. Central mechanisms and levodopa response fluctuations in Parkinson's disease. Clin Neuropharmacol 1988;11:378-85.

12 Klawans HL. L-Dopa-induced dyskinesias. In: The Pharmacology of Extrapyramidal Movement Disorders. Klawans HL, ed. Basel: S Karger, 1973:8-105.

13 Barbeau A. L-Dopa therapy in Parkinson's disease. A critical review of nine years experience. J Can Med Ass 1969; 110:59-68.

14 de Jong GJ, Meerwaldt JD, Schmitz PIM. Factors that influence the occurrence of response variations in Parkinson's disease. Ann Neurol 1987;22:4-7.

15 Mouradian MM, Juncos JL, Fabbrini G, et al. Motor fluctuations in Parkinson's disease: central pathophysiological mechanisms, part II. Ann Neurol 1988; 24:372-8.

16 Rajput AH, Stern W, Laverty WH. Chronic low-dose therapy in Parkinson's disease: an argument for delaying levodopa therapy. Neurology 1984;34:991-6.

17 Markham CH, Diamond SG. Long-term follow-up of early Dopa treatment in Parkinson's disease. Ann Neurol 1986;19:365-72.

18 Lesser RP, Fahn S, Snider SR, et al. Analysis of the clinical problems in Parkinsonism and the complications of long-term levodopa therapy. Neurology 1979;29. 1253-60.

19 Friedman A. Levodopa-induced dyskinesia: clinical observations. J Neurol 1985;232:29-31.

20 von Kummer R, Schneevoigt K. Früher oder später Beginn der L-Dopa behandlung bei M. Parkinson? Nervenarzt

21 Langston JW, Ballard P. Parkinsonism induced by 1methyl-4-phenyl-1,2,3,6-Tetrahydropyridine (MPTP): implications for treatment and pathogenesis of Parkinson's disease. Can J Neurol Sci 1984;11:160-5. 